\title{
Relationship Between Width of Maxillary Anterior Teeth and Interalar Distance
}

\author{
Mortaza Bonakdarchian and Reza Ghorbanipour
}

Isfahan University of Medical Sciences Hezar Jerib Avenue, Isfahan, Iran

ABSTRACT There are few guides to estimate the size of denture teeth. The purpose of this observational cross sectional study of Iranian adults was to evaluate the relationship between interalar width compared to intercanine tip distance and to the summed width of the maxillary anterior teeth in adults. The samples were selected from dental students in Isfahan University. Interalar width was measured with calipers. Maxillary inter-canine distance was measured between cusp tips on dental casts. Mesiodistal widths of the six anterior teeth also were measured. Independent t-tests, Pearson's correlation coefficients, and linear regression were used for statistical analysis. Mean interalar width was 36.38 $\mathrm{mm}(\mathrm{sd}=3.81)$, intercanine tip distance was $34.15 \mathrm{~mm}(\mathrm{sd}$ $=2.05)$, and mean width of maxillary anterior teeth was $48.23 \mathrm{~mm}(\mathrm{sd}=2.07)$. There were significant associations between interalar width and summed widths of the maxillary anterior teeth and with intercanine distance. In addition, predictive equations for estimation of tooth sizes using interalar width were calculated by regression. These statistical relationships may also be useful forensically. Dental Anthropology 2010;23(2):53-56.
One of the confusing and difficult aspects of complete denture prosthodontics is the selection of appropriately sized maxillary anterior denture teeth (Hoffman et al., 1986). The anterior teeth are primarily selected to satisfy esthetic concerns. The esthetic restoration of edentulous patients has an important psychological effect (Sellen et al., 1999; Al-Wazzan, 2001; Frush and Fisher, 1955). Patients who receive their dentures expect them to appear similar to their previous natural teeth (Gomes et al., 2009). The mesiodistal width of teeth is a harder aspect to estimate than the proper height of the anterior artificial teeth (McArthur, 1985). Various guidelines have been suggested for determining the maxillary anterior teeth when preextraction records are not available, but different opinions have been reported regarding their usefulness (Sellen et al., 1999; Verjao and Nogueira, 2005). One of the methods for selecting artificial anterior teeth is using certain guides (Keng, 1960). Several anatomic measurements have been suggested, including bizygomatic width (BZW), interpupillary distance (IPD), interalar width (IAW), and intercommisural width (ICW) (Zlatarić et al., 2007). Different views have been reported on the significance of the interalar width in selection of anterior tooth sizes. Picard (1958) found that interalar width could be used to estimate widths of the maxillary anterior teeth. This was substantiated by Wehner et al. (1967) who suggested extending parallel lines from the lateral margins of the alae of the nose onto the labial surface of the maxillary occlusal rim to estimate positions of the inter-canine cusp tips.

Hoffman et al. (1986) stated that there is a correlation of 0.413 between IAW and intercanine tip distance (ICTD). A weaker correlation coefficient of 0.217 was observed between IAW and width of maxillary anterior teeth (WMAT). ICTD was 3\% greater than IAW and WMAT was 31\% greater than IAW. Aleem et al. (1997) reported that WMAT is $26 \%$ greater than IAW. Al-El-Sheikh and Al-Athel (1998) found significant associations between IAW with (1) ICTD and (2) WMAT, and WMAT was 56\% greater than IAW. Mavroskoufis and Ritchie (1981) found a positive association between nasal width and ICTD, which promotes its use in establishing the width of the anterior teeth. Latta et al. (1991) reported significant differences in the IAW and IPD between races and sexes.

The aims of the present study were to compare IAW, ICTD, and WMAT between males and females and to derive predictive equations from a group of Iranian adults.

\section{MATERIALS AND METHODS}

This was a cross-sectional study of Iranian young adults. The sample of convenience consists of dental students from Isfahan University. A total of 120 cases were analyzed (60 males; 60 females). Inclusion criteria were: at least 18 years old of Iranian descent; normal nose morphology without a history of rhinoplasty; intact maxillary six anterior teeth without history of orthodontic therapy; a Class I normal occlusion without a diastema, spacing or crowding; and well aligned teeth in the maxillary arch (Al-El-Sheikh and

Correspondence to: Reza Ghorbanipour, Department of Orthodontics, Faculty of Dentistry, Isfahan University of Medical Sciences, Hezar Jerib Ave., Isfahan, Iran 8174673461

Email: dr_ghorbanipour@yahoo.com 


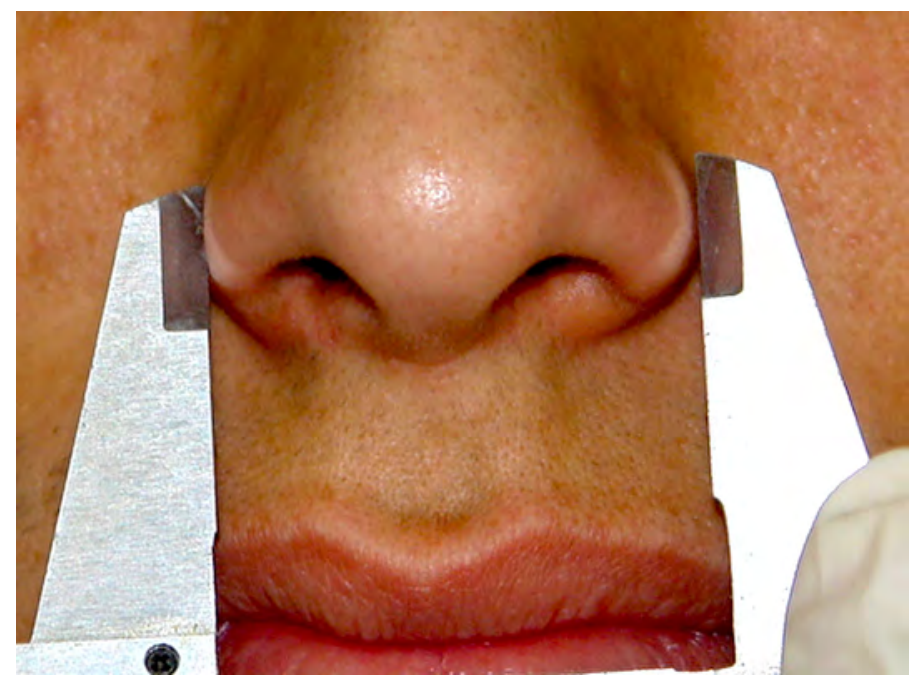

Fig. 1. Measurement of interalar width.

\section{Al-Athel, 1998; Hasanreisoglu et al., 2005).}

Sliding calipers were used with an accuracy of $0.1 \mathrm{~mm}$. Each distance was measured 3 times and the average was recorded (Gomes et al., 2009). IAW (Fig. 1) was measured from the widest point on either nostril (Zlatarić et al., 2007).

Irreversible hydrocolloid impressions (Cavex CA37, Cavex Holland, BV, Haarlenm, Holland) of the maxillary teeth were made and poured with hard dental stone (Begostone, BEGO, Bremen, Germany). The straightline distance between canine tips (Fig. 2) was measured (Hoffman et al., 1986). The maximum mesiodistal width of each anterior tooth was measured, and these widths were summed (coded as WMAT) (Gomes et al., 2009; Hasanreisoglu et al., 2005).

Descriptive statistics, independent t-tests, Pearson's correlation coefficient, and linear regression analysis were used for statistical analyses using the Statistical Package for Social Sciences (SPSS Inc., Chicago, IL, USA).

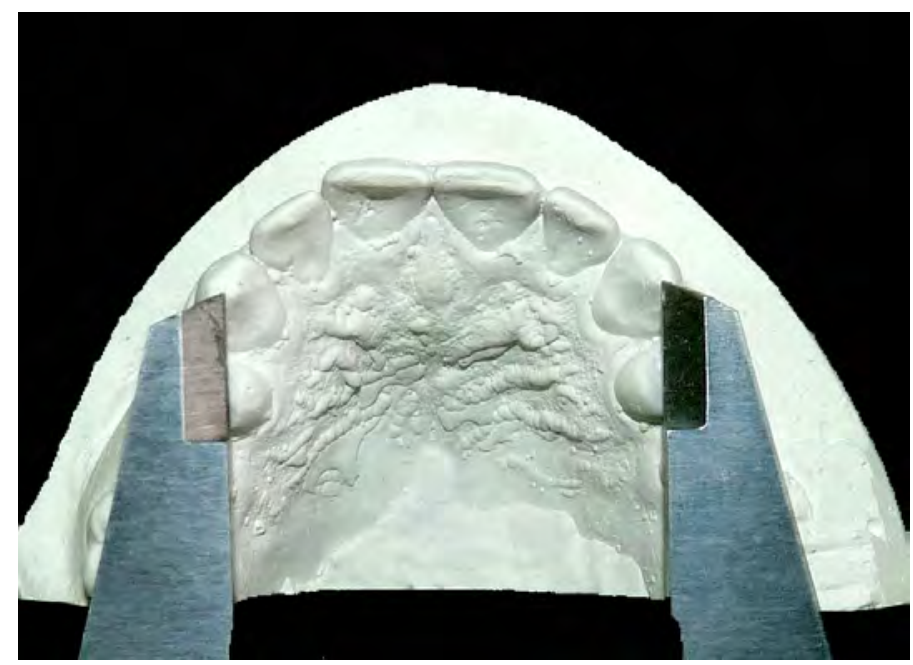

Fig. 2. Measurement of straight-line distance between the canine tips (intercanine tip distance)

\section{RESULTS}

Descriptive data are listed in Table 1. Results of independent $t$-tests show that the values of IAW, ICTD and WMAT were significantly greater in males than females. Pearson's $r$ disclosed significant associations between IAW and ICTD in females $(\mathrm{r}=0.457 ; \mathrm{P}<0.05)$ and in males $(\mathrm{r}=$ $0.442 ; \mathrm{P}<0.05)$ and between IAW and WMAT in females $(\mathrm{r}=0.473 ; \mathrm{P}<0.05)$ and in males $(\mathrm{r}=0.481 ; \mathrm{P}<0.05)$. The predictive equations for estimating tooth sizes from interalar width are summarized in Tables 2 and 3.

\section{DISCUSSION}

In earlier studies, measurements were made using extracted teeth. Recent studies measured tooth dimensions on casts or using computer-based images or intraoral evaluations (Hasanreisoglu et al., 2005). It is generally agreed that selection of the width of anterior teeth should be based on facial measurements and proportions (Al-ElSheikh and Al-Athel, 1998). It has been reported that the width of the nose may be used for selecting the size of the anterior teeth, for positioning the maxillary canines and for registering the curve of the anterior arch (Hoffman et al., 1986).

Sex differences in the dimensions of the anterior teeth have been noted for most racial groups, with men exhibiting mesiodistally wider teeth than women (e.g., Hasanreisoglu et al., 2005; Strett et al., 1992; Lavelle, 1972; Richardson and Malhotra, 1975).

The mean of IAW was $36.37 \mathrm{~mm}$ in the present study. It was smaller than the means reported by Mosharraf et al. $36.6 \mathrm{~mm}$ (2006), Latta and Weaver $43.9 \mathrm{~mm}$ (1991), Dharap and Tanuseputro (1997) $39.8 \mathrm{~mm}$ and was greater than the mean reported by Hoffman et al. (1986) at $34.28 \mathrm{~mm}$ and Al-El-Sheikh and Al-Athel (1998) at $33.27 \mathrm{~mm}$.

In the present study the mean of ICTD was $34.15 \mathrm{~mm}$, which is smaller than means reported by Dharap and

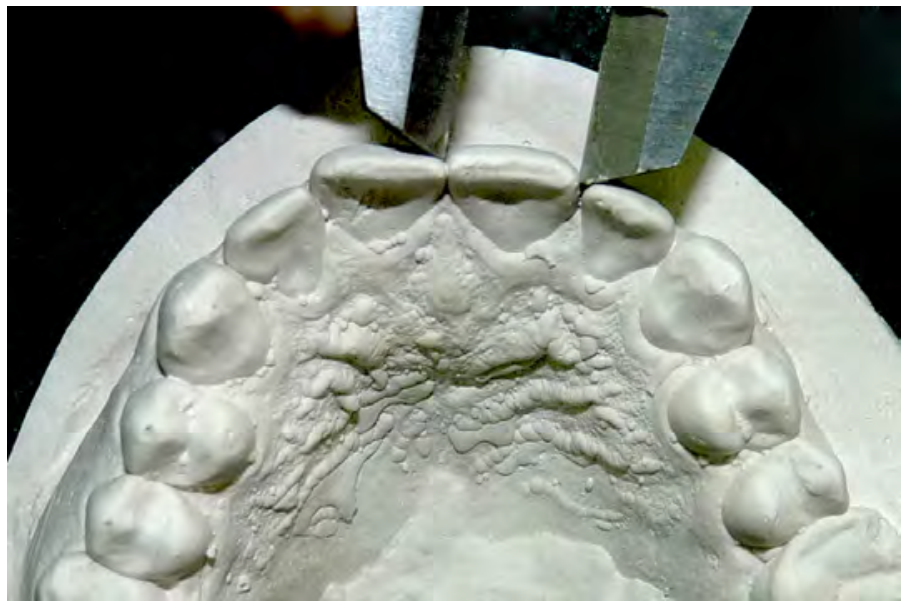

Fig. 3. Measurement of maximum mesiodistal width of maxillary incisor. 
TABLE 1. Descriptive statistics

\begin{tabular}{lrrrrr}
\hline \multicolumn{1}{c}{ Sex } & $\mathrm{n}$ & Mean & Max & Min & sd \\
\hline \multicolumn{7}{c}{ IAW $^{\dagger}$} \\
Female & 60 & 34.32 & 40.4 & 27.6 & 2.863 \\
Male & 60 & 38.43 & 47.5 & 30.8 & 3.549 \\
Total & 120 & 36.38 & 47.5 & 27.6 & 3.816 \\
\multicolumn{7}{c}{ ICTD } \\
Female & 60 & 33.25 & 36.3 & 29.1 & 1.735 \\
Male & 60 & 35.05 & 40.2 & 31.2 & 1.962 \\
Total & 120 & 34.15 & 40.2 & 29.1 & 2.052 \\
\multicolumn{7}{c}{ WMAT } \\
Female & 60 & 47.67 & 52.7 & 41 & 2.367 \\
Male & 60 & 48.78 & 54.6 & 40 & 2.873 \\
Total & 120 & 48.23 & 54.6 & 40 & 2.679 \\
\hline
\end{tabular}

tIAW, interalar width; ICTD, intercanine tip distance; WMAT, width of maxillary anterior teeth.

Tanuseputro (1997) $36.7 \mathrm{~mm}$ or Hoffman et al. (1986) 35.35 mm or Gomes et al. (2009) $37.44 \mathrm{~mm}$.

The mean of WMAT in this study $48.23 \mathrm{~mm}$ was smaller than the mean reported by Gomes et al. (2009) 53.67 and Al-El-Sheikh (1998) $52.22 \mathrm{~mm}$ and was greater than means reported by Hoffman et al. (1986) $44.85 \mathrm{~mm}$, Al-Wazzan (2001) $45.23 \mathrm{~mm}$ and Shillingburg et al. (1972) $45.80 \mathrm{~mm}$.

The differences among studies would seem to be due to ethnic differences or, possibly, different measurement techniques. Some studies used digital photography and obtained facial measurement from them, so they may have some errors because of the effect of the third dimension of anteroposterior length (Gomes et al., 2009; Hasanreisoglu et al., 2005), while others took measurements on the face (Hoffman et al., 1986; Al-El-Sheikh and Al-Athel, 1998; Mosharraf et al., 2006). Al-El-Sheikh and Al-Athel (1998) and Mosharraf et al. (2006) measured dental dimensions intraorally and Hoffman et al. (1986) used wax rim indices. Hasanreisoglu et al. (2005) and Gomes et al. (2009) measured dimensions from dental casts.

Genetic heritage would seem to be the main cause of variation between different groups (McArthur, 1985; Mavroskoufis and Ritchie, 1981). Participants in the current study were Iranian, and this is one source of the observed differences among groups.

There was a significant association between IAW and ICTD in females $(r=0.457 ; \mathrm{P}<0.05)$ and in males $(r=0.442$, $\mathrm{P}<0.05)$, which agrees with the studies of Hoffman et al. (1986) $(\mathrm{r}=0.49, \mathrm{P}<0.05)$, Mavroskoufis and Ritchie (1981), and Dharap and Tanuseputro (1997) $(\mathrm{r}=0.31, \mathrm{P}<0.05)$.
In the current study there was a significant relation between IAW and WMAT in females $(\mathrm{r}=0.473$; $\mathrm{P}<0.05)$ and in males ( $\mathrm{r}=0.481 ; \mathrm{P}<0.05)$. Hoffman et al. (1986), Mosharraf et al. (2006), and Al-El-Sheikh and Al-Athel (1998) reported similar associations in their studies $(\mathrm{P}<$ 0.05).

Concerning the estimation of ICTD from IAW, Hoffman et al. (1986) found the ratio of 1.31 between IAW and WMAT, this ratio was 1.30 in Gomes et al.'s study (2009) and 1.26 in a study conducted by Aleem et al. (1997) and 1.56 in Al-El-Sheikh and Al-Athel's study (1998). Other studies calculated the ratio of means, whereas we provide regression equations for estimating WMAT from IAW, which is more useful. Different results in this study are assumed to be due to different measurement methods, to ethnic differences, and to different methods of analyzing the data statistically.

From a clinical perspective, we promote the predictive equations in Tables 2 and 3 for estimating tooth sizes in Iranians. These equations will help dentists provide Iranian patients the best esthetics relative to their previous natural teeth and in harmony with their facial dimensions.

\section{CONCLUSIONS}

Within the limitations of the present study, the following conclusions were drawn:

1. The dimensions of IAW, ICTD and WMAT were larger in males.

2. There were significant relationships between IAW and ICTD and WMAT in each sex.

\section{ACKNOWLEDGEMENTS}

This study (No. 385074) was supported financially by Research Center of Isfahan University of Medical Sciences and Health Services), Isfahan, Iran. We are grateful to the department of prosthodontics in Isfahan faculty of dentistry and all the students who participated in this study.

\section{LITERATURE CITED}

Aleem, MA, Stipho HD, Talic YF, Khan N. 1997. The significance of inner canthal distance in prosthodontics. Saudi Dental J 9:36-39.

Al-El-Sheikh HM, Al-Athel MS. 1998. The relationship of inter pupillary width and maxillary anterior teeth width in Saudi population. Odonostomatol tropicale 21:7-10.

TABLE 2. Predictive equation for estimation of ICTD and WMAT from IAW in males $(Y=a+b X)$

\begin{tabular}{ccccl}
\hline Y & $\mathrm{X}$ & $\mathrm{r}$ & $\mathrm{P}$ value & \multicolumn{1}{c}{ Predictive equation } \\
\hline ICTD & IAW & 0.442 & $<0.0001$ & ICTD $=26.143+0.216 \times$ IAW \\
WMAT & IAW & 0.481 & 0.0080 & WMAT $=43.807+0.129 \times$ IAW \\
\hline
\end{tabular}


TABLE 3. Predictive equation for estimation of ICTD and WMAT from IAW in females $(Y=a+b X)$

\begin{tabular}{ccccc}
\hline Y & X & r & P value & Predictive equation \\
\hline ICTD & IAW & 0.457 & 0.016 & ICTD $=28.187+0.145 \times$ IAW \\
WMAT & IAW & 0.473 & 0.000 & WMAT $=42.194+0.159 \times$ IAW \\
\hline
\end{tabular}

Al-Wazzan KA. 2001. The relationship between intercanthal dimension and width of maxillary anterior teeth. J Prosthet Dent 88:608-612.

Dharap AS, Tanuseputro H. 1997. A comparison of interalar width and intercanine distance in Malay males and females. Anthropol Anz 55:63-68.

Frush JP, Fisher DR. 1955. Introduction to dentogenic restorations. J Prosthet Dent 5:586-595.

Gomes VL, Gonçalves LC, Costa MM, Lucas Bde L. 2009. Interalar distance to estimate the combined width of the six maxillary anterior teeth in oral rehabilitation treatment. J Esthet Restor Dent 21:26-35.

Hasanreisoglu U, Berksun S, Aras K, Arsalan I. 2005. An analysis of maxillary anterior teeth: facial and tooth proportions. J Prosthet Dent 94:530-538.

Hoffman W Jr, Bombery TJ, Hatch RA. 1986. Interalar width as a guide in denture tooth selection. J Prosthet Dent 55:219-221

Keng SB. 1960. Nasal width dimension and anterior teeth in prosthodontics. Ann Acad Med Singapore 15:311314.

Latta GH Jr, Weaver JR, Conkin JE. 1991. The relationship between the width of the mouth, interalar width, bizygomatic width and interpupillary distance in edentulous patients. J Prosthet Dent 65:250-254.

Lavelle CL. 1972. Maxillary and mandibular tooth size in different racial groups and in different occlusal categories. Am J Orthod 61:29-37. Young HA (1954) . Selecting anterior tooth mold. J Prosthet Dent 4:748760.

Mavroskoufis F, Ritchie GM. 1981. Nasal width and incisive papilla as guides for the selection and arrangement of maxillary anterior teeth. J Prosthet Dent 45:592-597.

McArthur DR. 1985. Determining approximate size of maxillary anterior artificial teeth when mandibular anterior teeth are present. Part I: size relationship. J Prosthet Dent 53:216-218.
Mosharraf R. Sadeghian S, Farzan A, Malekzadeh F. 2006. The relationship between the mesiodistal width of maxillary incisors and width of the mouth, interalar width, Bizygomatic width and intercanthal distance. Int J Dental Anthropology 8:22-30.

Picard JR. 1958. Complete denture esthetics. J Prosthet Dent 8:252-259.

Richardson ER, Malhotra SK. 1975. Mesiodistal Crown dimension of the permanent dentition of American Negroes. Am J Orthod 68:157-164.

Sellen PN, Phil B, Jagger DC, Harrison A. 1999. Methods used to select artificial anterior teeth for the edentulous patient: a historical overview. Int J Prosthodont 1999;12:51-58.

Shilllingburg HT Jr, Kaplan MJ, Grace SC. 1972. Tooth dimension, a comparative Study. J So Calif Dent Assoc 40:830-839.

Strett JD Oliver T, Robinson F, Fortson W, Knaak B, Russel CM. 1992. Width/length ratios of normal clinical crowns of the maxillary anterior dentition in men. J Clin Periodontol 26:153-157.

Verjao FM, Nogueira SS. 2005. Intercommisural width in 4 racial groups as a guide for selection of maxillary anterior teeth in complete dentures. Int J Periodontol 18:513-515.

Wehner PJ, Hickey JC, Boucher CO. 1967. Selection of artificial teeth. J Prosthet Dent 18:222-232.

Zlatarić DK, Kristek E, Celebić A. 2007. Analysis of width/ length ratios of normal clinical crowns of the maxillary anterior dentition: correlation between dental proportions and facial measurements. Int J Prosthodont 20:313-315. 